\title{
Self-assessment of striae gravidarum prophylaxis
}

\author{
Bogusław Antoszewski ${ }^{1}$, Małgorzata Sobczak², Anna Kasielska-Trojan ${ }^{1}$
}

${ }^{1}$ Plastic, Reconstructive and Aesthetic Surgery Clinic, Institute of Surgery, Medical University of Lodz, Lodz, Poland Head of the Department: Bogusław Antoszewski MD, PhD, Prof. MUL 2Obstetrics Out-patient Department, Polish Mother's Memorial Hospital-Research Institute, Lodz, Poland Head of the Department: Piotr Woźniak MD, PhD, Prof. PMMHRI

Postep Derm Alergol 2015; XXXII (6): 459-464

DOI: $10.5114 /$ pdia.2015.56100

\begin{abstract}
Introduction: Striae are the most frequently occurring pathology of connective tissue during pregnancy. According to the statistical data, $70-90 \%$ of women suffer from striae gravidarum.

Aim: To assess effectiveness of topical products and massage used by pregnant women in striae gravidarum prophylaxis.

Material and methods: The questionnaire study was conducted among 299 women who were maximum 6 months after delivery at term. The questionnaire included questions concerning age, occurrence of striae gravidarum during pregnancy, their location, week of gestation when the lesions appeared and used striae prophylaxis as well as its effectiveness in respondents' opinion.

Results: Analysis of the correlation between striae gravidarum occurrence and use of different types of cosmetics showed that this kind of prophylaxis is effective when applied at least twice a day (63.7\% vs. $77.6 \%$ ). No correlation between the type of cosmetics and presence of striae was observed $(p>0.05)$.

Conclusions: Use of prophylactic measures like skin emollients and oils with the appropriate frequency significantly reduces the risk of striae gravidarum occurrence.
\end{abstract}

Key words: striae, pregnancy, prophylaxis.

\section{Introduction}

Stretch marks (striae) are skin lesions present in numerous physiological and pathological conditions. Based on lesions' etiology, many types can be distinguished and the most common ones are striae gravidarum [1]. They are a benign form of skin changes occurring during pregnancy and are dependent on physiological hormonal changes [2]. It is highlighted in the literature that they are the most frequently occurring pathology of connective tissue during pregnancy. According to the statistical data, $70-90 \%$ of women suffer from striae gravidarum and most commonly the lesions appear primarily in the twenty-fourth week of pregnancy [3-6]. Clinically they take the form of line scaring, which first (in the inflammatory phase) is reddish or purple and tends to fade gradually. In the atrophic phase, striae take the form of atrophic lines, varying in size and hypopigmentation level. Striae gravidarum are most likely to appear in the following locations: abdomen, breasts, buttocks, thighs and hips [3].
Prevalence of striae gravidarum and the fact that they cause significant aesthetic disturbances result in specialists' increasing interest in the topic of their prophylaxis and treatment [3, 4]. Researches dealing with this problem focus on evaluation of most commonly used prophylactic methods' effectiveness as well as on searching for striae risk factors, especially those modifiable [7].

In the literature, studies concerning efficacy of some topical preparations in striae gravidarum prophylaxis can be found, for example researches on creams comprising cocoa butter. However many authors negate the effectiveness of such therapy [8-11]. Osman et al. and Buchanan et al. on the basis on their studies concluded that application of cocoa butter does not reduce the risk of striae occurrence $[8,9]$. On the other hand, promising results were obtained in the case of the use of Trofolastin containing the extract from Centella Asiatica, and retinoic acid-based topical creams [10-12]. Nevertheless, attention should be paid to the safety of topical tretinoin use during pregnancy and breast feeding. In the literature,

Address for correspondence: Bogusław Antoszewski MD, PhD, Ass. Prof., Plastic, Reconstructive and Aesthetic Surgery Clinic, Medical University of Lodz, 22 Kopcinskiego St, Lodz 90-153, Poland, phone: +48 4267767 42, fax: +48 4267767 49, e-mail: b.antoszewski@wp.pl Received: 9.11.2013, accepted: 10.02.2014. 
there are reports of birth defects associated with topical tretinoin use, which are consistent with retinoid embryopathy [13-16]. Due to the fact that the role of the topical retinoids in these cases remains controversial, studies' results are inconsistent and there is no evidence for safety of topical tretinoin use during pregnancy and breast feeding, such treatment should not be used [17, 18].

Moreover, it was claimed that regular massage of the body areas predisposed to striae occurrence can result in decrease in the number and severity of these lesions [19].

\section{Aim}

The aim of this study is to assess effectiveness of topical products and massage used by pregnant women in striae gravidarum prophylaxis.

\section{Material and methods}

The study was conducted at the Plastic, Reconstructive and Esthetic Surgery Clinic and in the Obstetrics

Table 1. Correlation between the use of different types of cosmetics and massage and occurrence of striae gravidarum (SG)

\begin{tabular}{llll}
\hline Variable & SG, $n(\%)$ & No SG, $n(\%)$ & Value of $p$ \\
\hline Use of cosmetics: & & & 0.4364 \\
\hline Yes & $172(72.3)$ & $66(27.7)$ & \\
\hline No & $41(67.2)$ & $20(32.8)$ & \\
\hline Massage: & & & 0.3386 \\
\hline Yes & $67(67.7)$ & $32(32.3)$ & \\
\hline No & $146(73)$ & $54(27)$ & \\
\hline Type of cosmetic: & & & 0.2457 \\
\hline No & $41(67.2)$ & $20(32.8)$ & \\
\hline Classic & $87(74.4)$ & $30(25.6)$ & \\
\hline Specialist & $69(74.2)$ & $24(25.8)$ & \\
\hline Both types & $16(57.1)$ & $12(42.9)$ & \\
\hline Type of cosmetic: & & & 0.1634 \\
\hline Classic & $87(74.4)$ & $30(25.6)$ & \\
\hline Specialist & $69(74.2)$ & $24(25.8)$ & \\
\hline Both types & $16(57.1)$ & $12(42.9)$ & \\
\hline Frequency: & & & \\
\hline Once a day & $114(77.6)$ & $33(22.4)$ & \\
\hline Twice a day or more & $58(63.7)$ & $33(36.3)$ & \\
\hline Tested with $\chi^{2}$ test. & & & \\
\hline
\end{tabular}

Outpatient Department. All the Clinic and the Outpatient Department patients who were maximum 6 months after delivery at term were asked to participate in the study, irrespective of whether they were primiparas or multiparas. To obtain a homogenous group, only Caucasian patients were included in the study. The period of data collection was 6 months. Finally, a total of 299 women met the criteria and gave their consent to take part in the study.

For the purpose of this retrospective study, a questionnaire designed by the authors was prepared and was filled in by the examined women during the medical examination. The questionnaire included questions concerning: age, number of pregnancies, occurrence of striae gravidarum during pregnancy, their location (assessed by the respondents and verified by the doctor) and week of gestation when the lesions appeared. Moreover, women were asked about striae prophylaxis used as well as its effectiveness in their opinion. Respondents answered the following questionnaire items: if they used cosmetics to prevent striae development, what type of preparations they used (with brand names of the cosmetics), if they performed massage of the areas predisposed to striae occurrence, what the frequency of cosmetic usage was (once, twice, three or more times a day), if used preparations were effective, stopped striae development and made lesions less visible, and if respondents would recommend using cosmetics against striae during pregnancy.

In the questionnaire, possible answers were defined on a 5-point scale as: "definitely yes", "rather yes", "I do not have an opinion", "rather no" and "definitely no". In the statistical analysis, "rather yes" and "rather no" answers were added to "definitely yes" and "definitely no" answers and finally three options were considered: "yes", "no" and "I do not have an opinion".

On the basis of women's answers concerning cosmetics used, the preparations were divided into two groups, "classic" and "specialist". The division was based on the analysis of cosmetics" ingredients. As "classic" the authors qualified moisturizing preparations and emollients (balms, creams and oils) without active ingredients and as "specialist" - formulations against striae (as declared by the manufacturer) and/or containing different types of active ingredients (e.g.. cocoa and shea butter, plant extracts).

\section{Statistical analysis}

The results were statistically analyzed with $\chi^{2}$ test using Statistica 8.0. As a level of significance $p<0.05$ was accepted.

\section{Results}

The mean age of the examined women was $27.8 \pm 4.2$ years. Most of the respondents $(n=185 ; 61.9 \%)$ were primiparas, the rest bore two $(n=100)$ or three times 
Table 2. Women's assessment of different types of cosmetics' effectiveness

\begin{tabular}{|c|c|c|c|c|}
\hline Variable & Classic, $n$ (\%) & Specialist, $n(\%)$ & Both types, $n$ (\%) & Value of $p$ \\
\hline Effectiveness: & & & & 0.0010 \\
\hline Yes & $41(35)$ & 39 (41.9) & $22(78.6)$ & \\
\hline No opinion & $42(35.9)$ & $26(28)$ & $2(7.1)$ & \\
\hline No & $34(29.1)$ & $28(30.1)$ & $4(14.3)$ & \\
\hline Stop striae development: & & & & $<0.0001$ \\
\hline Yes & $24(20.5)$ & $17(18.3)$ & $24(85.7)$ & \\
\hline No opinion & $64(54.7)$ & $49(52.7)$ & $3(10.7)$ & \\
\hline No & $29(24.8)$ & $27(29)$ & $1(3.6)$ & \\
\hline Make lesions less visible: & & & & $<0.0001$ \\
\hline Yes & $32(27.4)$ & $17(18.3)$ & $18(64.3)$ & \\
\hline No opinion & $53(45.3)$ & $55(59.1)$ & $0(0)$ & \\
\hline No & $32(27.4)$ & $21(22.6)$ & $10(35.7)$ & \\
\hline
\end{tabular}

Tested with $\chi^{2}$ test.

$(n=14)$. Among the women participating in the study, $213(71.2 \%)$ developed striae gravidarum. Taking into consideration all sites involved, lesions occurred on the abdomen $(n=149)$, the breasts $(n=125)$, the buttocks $(n=50)$, and on the thighs $(n=41)$. Most often women observed striae in the second $(n=102)$ or in the third trimester $(n=101)$.

Analysis of the correlation between striae gravidarum occurrence and the use of different types of cosmetics showed that this kind of prophylaxis is effective when applied at least twice a day (63.7\% vs. $77.6 \%)$. Also influence of used cosmetics' type was analyzed, taking into account their division into "classic" and "specialist". No correlation between the type of cosmetics and presence of striae was observed $(p>0.05)$ (Table 1).

It was also checked if a type of used cosmetics influenced a subjective assessment of their effectiveness. It was found that women who simultaneously used cosmetics from both groups expressed a significantly better opinion about the products (their effectiveness, ability to stop striae development and to make lesions less visible) ( $p<0.0001$ ). Among these women, $78.6 \%$ claimed that prophylaxis they used is effective, while a similar opinion was expressed by 35\% women using only "classic" cosmetics and by $41.9 \%$ respondents using "specialist" creams $(p<0.05)$. Similar results were obtained in questions concerning ability to stop striae development and to make lesions less visible (Table 2).

It was also assessed if the frequency of cosmetics' use influences women's evaluation of their effectiveness. Respondents who used cosmetics at least twice a day significantly more frequently reported that products stopped striae development than those respondents who used preparations once a day $(p<0.05)$ (Table 3).
The correlation between cosmetics and massage effectiveness and striae locations was also analyzed. It was found that striae gravidarum on breasts appeared significantly less frequently in respondents who used both "classic" and "specialist" cosmetics ( $p<0.05)$ (Table 4).

The results showed that women who expressed a positive opinion about used cosmetics significantly more often claimed that these products should be used in striae prophylaxis than those who had a negative opinion or did not have any opinion on this topic $(p<0.05)$ (Table 5).

Table 3. Women's assessment of cosmetics' effectiveness in relation to the frequency of their use

\begin{tabular}{llll}
\hline Variable & $\begin{array}{c}\text { Once } \\
\text { a day, } \\
n(\%)\end{array}$ & $\begin{array}{c}\text { Twice } \\
\text { a day } \\
\text { or more, } \\
n(\%)\end{array}$ & Value of $p$ \\
\hline Effectiveness: & $55(53.9)$ & $47(46.1)$ & 0.0632 \\
\hline Yes & $50(71.4)$ & $20(28.6)$ & \\
\hline No opinion & $42(63.6)$ & $24(36.4)$ & \\
\hline No & $27(41.5)$ & $38(58.5)$ & \\
\hline Stop striae development: & $85(73.3)$ & $31(26.7)$ & \\
\hline Yes & $35(61.4)$ & $22(38.6)$ & \\
\hline No opinion & & & \\
\hline No & $34(50.7)$ & $33(49.3)$ & \\
\hline Make lesions less visible: & $74(68.5)$ & $34(31.5)$ & \\
\hline Yes & $39(61.9)$ & $24(38.1)$ & \\
\hline No opinion & & & \\
\hline No & & & \\
\hline
\end{tabular}

Tested with $\chi^{2}$ test. 
Table 4. Correlation between the use of different types of cosmetics and massage and occurrence of striae gravidarum in different locations (SG)

\begin{tabular}{|c|c|c|c|}
\hline Variable & SG - breast, $n(\%)$ & No SG - breast, $n(\%)$ & Value of $p$ \\
\hline Type of cosmetic: & & & 0.0021 \\
\hline Classic & $53(45.3)$ & $64(54.7)$ & \\
\hline Specialist & $48(51.6)$ & $45(48.4)$ & \\
\hline Both types & $4(14.3)$ & $24(85.7)$ & \\
\hline Massage: & & & 0.0657 \\
\hline Yes & $34(34.3)$ & $65(65.7)$ & \\
\hline \multirow[t]{2}{*}{ No } & $91(45.5)$ & $109(54.5)$ & \\
\hline & SG - abdomen, $n(\%)$ & No SG - abdomen, $n$ (\%) & \\
\hline Type of cosmetic: & & & 0.3127 \\
\hline Classic & $66(56.4)$ & $51(43.6)$ & \\
\hline Specialist & $45(48.4)$ & $48(51.6)$ & \\
\hline Both types & $12(42.9)$ & $16(57.1)$ & \\
\hline Massage: & & & 0.0714 \\
\hline Yes & $42(42.4)$ & $57(57.6)$ & \\
\hline \multirow[t]{2}{*}{ No } & $107(53.5)$ & $93(46.5)$ & \\
\hline & SG - buttocks, $n(\%)$ & No SG - buttocks, $n$ (\%) & \\
\hline Type of cosmetic: & & & 0.3769 \\
\hline Classic & $21(17.9)$ & $96(82.1)$ & \\
\hline Specialist & $16(17.2)$ & $77(82.8)$ & \\
\hline Both types & $8(28.6)$ & $20(71.4)$ & \\
\hline Massage: & & & 0.2566 \\
\hline Yes & $20(20.2)$ & 79 (79.8) & \\
\hline \multirow[t]{2}{*}{ No } & $30(15)$ & $170(85)$ & \\
\hline & SG - thighs, $n(\%)$ & No SG - thighs, $n(\%)$ & \\
\hline Type of cosmetic: & & & 0.4527 \\
\hline Classic & $12(10.3)$ & $105(89.7)$ & \\
\hline Specialist & $9(9.7)$ & $84(90.3)$ & \\
\hline Both types & $5(17.9)$ & $23(82.1)$ & \\
\hline Massage: & & & 0.3864 \\
\hline Yes & $16(16.2)$ & 83 (83.8) & \\
\hline No & 25 (12.5) & 175 (87.5) & \\
\hline
\end{tabular}

Tested with $\chi^{2}$ test.

\section{Discussion}

This research showed that striae gravidarum are common skin lesions, as their occurrence was reported by $70 \%$ of respondents. In the examined group, most frequently striae appeared on the abdomen and breasts. Similar observations concerning lesions' locations were presented by Osman et al. who disclosed that most commonly they are observed on the abdomen, thighs and breast [3]. 
Our study showed that the majority of women used cosmetics against striae during pregnancy (79.6\%). Moisturizing and lipid-replenishing cosmetics without additional active ingredients were most commonly used (39\%). Cosmetics "against striae" which, according to the manufacturer's declaration, contained different types of active ingredients (31\%) were less popular. Statistically, no correlation between using "classic" and "specialist" cosmetics, and striae occurrence was observed. Similar results were obtained by Madlon-Kay whose study confirmed women's interest in cosmetics claimed to prevent striae. She found that women who attempted to prevent striae using different kinds of prophylactic measures developed lesions as often as those who made no such attempt. The author suggests that popularity of cosmetics against striae is connected with the fact that creams, oils or cocoa butter are mentioned as effective prophylaxis in many commercial pregnancy guides [20, 21]. Moreover, lack of evidence of cocoa butter efficacy in striae prophylaxis was shown in many clinical researches [9, 22]. Soltanipoor et al. whose study aimed to evaluate the effect of olive oil in prevention of striae gravidarum also observed no significant reduction in the incidence and the severity of lesions, so they did not recommend it for striae prevention [23]. Promising results were obtained in the case of a prophylactic use of anti-striae cream Trofolastin (Centella Asiatica extract, $\alpha$-tocopherol, and collagen-elastin hydrolysates) and Verum (containing vitamin E, panthenol, hyaluronic acid, elastin and menthol). However, the observed positive effect might be a result of the massage itself rather than cosmetics' ingredients [10-12]. On the basis of the results of a randomized double-blinded study, Garcia Hernández et al. proved effectiveness of anti-striae emollient and moisturizer containing hydroxyprolisilane C, rosehip oil, Centella Asiatica triterpenes and vitamin E [24]. Our study showed that systematic use of cosmetics at least twice per day significantly reduces the risk of striae occurrence. The results indicate that the type of cosmetic (with or without active ingredients) is not relevant in striae prophylaxis while frequency of its use is crucial in effective prevention of these lesions.

Most of the examined women do not have an opinion on effectiveness of the used products in reducing severity of the striae and in halting progression of those already present. The best subjective opinion on the effectiveness of the cosmetics used was expressed by the respondents who used products from both groups. This may result from a higher frequency and regularity of using cosmetics in this group. Most of the examined respondents regard using cosmetics against striae formation as appropriate, however women who claimed the cosmetics to be effective, significantly more often would recommend such prophylaxis. It should be highlighted that further studies are needed to verify safety and effectiveness of products with different active ingredients used in pregnant women. Verification of topical cosmetics in striae
Table 5. Women's assessment of cosmetics' effectiveness in relation to their recommendations

\begin{tabular}{lccc}
\hline Variable & $\begin{array}{c}\text { Should } \\
\text { be used, } \\
n(\%)\end{array}$ & $\begin{array}{c}\text { Against } \\
\text { using, } \\
n(\%)\end{array}$ & Value of $p$ \\
\hline Effectiveness: & $96(94.1)$ & $6(5.9)$ & 0.0030 \\
\hline Yes & $59(84.3)$ & $11(15.7)$ & \\
\hline No opinion & $50(75.8)$ & $16(24.2)$ & \\
\hline No & $63(96.9)$ & $2(3.1)$ & 0.0001 \\
\hline Stop striae development: & $102(87.9)$ & $14(12.1)$ & \\
\hline Yes & $40(70.2)$ & $17(29.8)$ & \\
\hline No opinion & & & 0.0499 \\
\hline No & $63(94)$ & $4(6)$ & \\
\hline Make lesions less visible: & & & \\
\hline Yes & $92(85.2)$ & $16(14.8)$ & \\
\hline No opinion & $50(79.4)$ & $13(20.6)$ & \\
\hline No & & & \\
\hline
\end{tabular}

Tested with $\chi^{2}$ test.

gravidarum prevention should be performed before these treatments can be recommended as striae prophylaxis $[25,26]$.

The presented study has, however, some limitations: assessment of the used prophylaxis was based on respondents' subjective opinion and no objective scale was applied for unification of striae description.

\section{Conclusions}

Topical cosmetics, regardless their type, do not reduce the risk of striae gravidarum development. Use of prophylactic measures like skin emollients and oils with the appropriate frequency significantly reduces risk of striae gravidarum. In women's subjective opinion, use of both "classic" and "specialist" products is the most effective prevention of striae and they regard using this kind of prophylaxis as appropriate.

\section{Conflict of interest}

The authors declare no conflict of interest.

\section{References}

1. Murray JC. Pregnancy and the skin. Dermatol Clin 1990; 8: 327-34.

2. Tunzi M, Gray GR. Common skin conditions during pregnancy. Am Fam Physician 2007; 75: 211-8.

3. Osman H, Rubeiz N, Tamim H, Nassar AH. Risk factors for the development of striaegravidarum. Am J Obstet Gynecol 2007; 196: 62.e1-5. 
4. Ghasemi A, Gorouhi F, Rashighi-Firoozabadi M, et al. Striaegravidarum: associated factors. J Eur Acad Dermatol Venereol 2007; 21: 743-6.

5. Kroumpouzos G, Cohen LM. Dermatoses of pregnancy. J Am Acad Dermatol 2001; 45: 1-19.

6. Muzaffar F, Hussain I, Haroon TS. Physiologic skin changes during pregnancy: a study of 140 cases. Int J Dermatol 1998; 37: 429-31.

7. Kasielska-Trojan A, Ratajczyk K, Antoszewski B. Wpływ pigmentacji i fototypu skóry na występowanie rozstępów niezwiązanych z ciążą. Pol J Cosmetol 2012; 15: 187-91.

8. Osman H, Usta IM, Rubeiz N, et al. Cocoa butter lotion for prevention of striaegravidarum: a double-blind, randomised and placebo-controlled trial. BJOG 2008; 115: 1138-42.

9. Buchanan K, Fletcher HM, Reid M. Prevention of striaegravidarum with cocoa butter cream. Int J Gynaecol Obstet 2010; 108: 65-8.

10. Young GL, Jewell D. Creams for preventing stretch marks in pregnancy. Cochrane Database Syst Rev 2000; 2: CD000066.

11. Rangel O, Arias I, García E, Lopez-Padilla S. Topical tretinoin $0.1 \%$ for pregnancy-related abdominal striae: an open-label, multicenter, prospective study. Adv Ther 2001; 18: 181-6.

12. Mallol J, Belda MA, Costa D, et al. Prophylaxis of Striaegravidarum with a topical formulation. A double blind trial. Int J Cosmet Sci 1991; 13: 51-7.

13. Lipson AH, Collins F, Webster WS. Multiple congenital defects associated with maternal use of topical tretinoin. Lancet 1993; 341: 1352-3.

14. Jick SS, Terris BZ, Jick H. First trimester topical tretinoin and congenital disorders. Lancet 1993; 341: 1181-2.

15. Navarre-Belhassen C, Blanchet P, Hillaire-Buys D, et al. Multiple congenital malformations associated with topical tretinoin. Ann Pharmacother 1998; 32: 505-6.

16. Selcen D, Seidman S, Nigro MA. Otocerebral anomalies associated with topical tretinoin use. Brain Dev 2000; 22: 218-20.

17. Shapiro L, Pastuszak A, Curto G, Koren G. Safety of firsttrimester exposure to topical tretinoin: prospective cohort study. Lancet 1997; 350: 1143-4.

18. Loureiro KD, Kao KK, Jones KL, et al. Minor malformations characteristic of the retinoic acid embryopathy and other birth outcomes in children of women exposed to topical tretinoin during early pregnancy. Am J Med Genet A 2005; 136: 117-21.

19. TimurTaşhan S, Kafkasli A. The effect of bitter almond oil and massaging on striaegravidarum in primiparaous women. J Clin Nurs 2012; 21: 1570-6.

20. Madlon-Kay DJ. Striaegravidarum. Folklore and fact. Arch Fam Med 1993; 2: 507-11.

21. Hotchner T. Pregnancy and childbirth: the complete guide for a new life. New York, NY: Avon Books; 1984; 115-6.

22. Brennan M, Young G, Devane D. Topical preparations for preventing stretch marks in pregnancy. Cochrane Database Syst Rev 2012; 11: CD000066.

23. Soltanipoor F, Delaram M, Taavoni S, Haghani H. The effect of olive oil on prevention of striaegravidarum: a randomized controlled clinical trial. Complement Ther Med 2012; 20: 263-6.

24. García Hernández JÁ, Madera González D, Padilla Castillo M, Figueras Falcón T. Use of a specific anti-stretch mark cream for preventing or reducing the severity of striaegravidarum. Randomized, double-blind, controlled trial. Int J Cosmet Sci 2013; 35: 233-7.
25. Ernst E. Herbal medicinal products during pregnancy: are they safe? BJOG 2002; 109: 227-35.

26. Al-Himdani S, Ud-Din S, Gilmore S, Bayat A. Striaedistensae: a comprehensive review and evidence-based evaluation of prophylaxis and treatment. Br J Dermatol 2014; 170: 527-47. 